\title{
The oral and silent reading ability of grade seven students of Calamba Bayside Integrated School
}

Dela Cruz, Rosita L. $\$

Laguna College of Business and Arts, Philippines (rosita.delacruz007@deped.gov.ph)

Recillo, Maria Luisa B.

City College of Calamba, Philippines

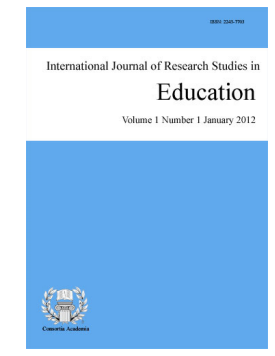

ISSN: 2243-7703 Online ISSN: 2243-7711

OPEN ACCESS DOI: $10.5861 /$ ijrse.2021.a082

\section{Abstract}

The main objective of the study was to determine the oral and silent reading ability level in English of Grade seven students enrolled during the school year 2019-2020 in Calamba Bayside Integrated School, Calamba City, Laguna. The study made use of the descriptive research design using the Philippine Informal Inventory (Phil-IRI) materials - focusing on fluency and comprehension. The participants of the study were the 150 grade seven students. The statistical tools used were frequency count and percentage distribution, the mean and standard deviation, t-test, and analysis of variance. Findings revealed that in Oral Reading, majority of the participants were classified under the Frustration level in fluency, while they came out to be at the Instructional level in comprehension. In Silent Reading, the participants were classified under the Frustration level in both fluency and comprehension. Also, it was revealed that there was a significant difference between the oral and silent reading ability level of students when analyzed in terms of their fluency and comprehension. The results led to the conclusion that in oral reading, majority of the students could not read materials on their own as evidenced by their low rate in Fluency. In terms of Comprehension, the students could understand the material but only with some assistance from the teacher. The reading level of the students in oral and silent reading was the same - at the Frustration level. As for Comprehension, they read better aloud (Instructional level) than quietly (Frustration level) since they were helped by their teacher while reading. Results from the said studies served as basis for the suggested enhancement program to improve the oral and silent reading ability of the students.

Keywords: oral reading, silent reading, reading fluency, reading comprehension, instructional level 


\section{The oral and silent reading ability of grade seven students of Calamba Bayside Integrated School}

\section{Introduction}

The generation today lives in a fast-paced and highly computerized society. As years go by, the demands have become greater and keeping up with them requires more effort and time. However, all these things would not have been made possible if people did not know how to read. Reading is essential to man's existence. Gray (2013) expressed this more vividly when he said, "Reading is an indispensable factor in modern life, interwoven with work, recreation, and other activities of young people and adults. If a person wishes to be well informed, enjoy his existence and relationship with others, he must know how to read." People can be full-grown individuals armed with knowledge, wisdom, and refined manners if they do read. Aside from that, reading various write-ups upgrades one's aptitudes in spelling, comprehension, and vocabulary. Francis Bacon (2015) gave emphasis to this when he said, "Reading makes a full man, conference a ready man, and writing an exact man," a quotation that up to this time has become a favorite of the adherents of the famous saying.

Reading does not only entail knowing the meaning of a word by recalling its meaning. It is also an activity wherein the reader tries to organize said meaning. According to Bond (2013), the organization of meaning is governed by purposes that are clearly defined by the reader. In short, the reading process involves both the acquisition of meaning intended by the writer and the reader's own contribution in the form of interpretation and evaluation. Throughout one's life, one has to do a lot of reading. It is therefore necessary that one knows how to apply these reading skills appropriately. Understanding words, sentences, and paragraph is essential to comprehending reading selections.

In school, reading is the heart of the curriculum. The child who cannot read is handicapped because he does not process an important tool where he can obtain his formal education. Many studies have shown that failures in other subjects have been due to misbehavior in reading. In as much as teachers bear the major responsibility in the education of the child, it is important that they strive hard to work out ways of improving instruction, especially in reading. The major role or goal of reading instruction is to foster in students the ability to interact with and to understand the printed language. Persons who are contented with what they already know will soon find themselves lagging their peers no matter what their fields of endeavor are.

One of the major tools used in the reading program today to determine the strength and weaknesses of the students is the Philippine Individual Reading Inventory (Phil-IRI) which is an authentic reading assessment that attempts to evaluate reading in a way that is more closely aligned to their performance. The Phil-IRI is a series of reading passages that are arranged in order of difficulty and is accompanied by comprehension questions. It is an informal measure that can assess the child's use of comprehension, vocabulary, and word identification strategies within context.

The Phil-IRI Oral Reading Test is administered in order to identify the student's miscues in oral reading; record the number of words that a student reads per minute; and find out how well a student understands the passage read. When used to assess oral reading skills, the Phil-IRI may be used to describe decoding and word recognition, fluency, and comprehension. The student's performance in decoding (the ability to read isolated words using phonics knowledge) and word recognition (the ability to automatically identify words on sight) is measured through a Reading Miscue. The child is asked to read a passage and each word read incorrectly is noted and marked.

In terms of fluency (the ability to read with speed, accuracy, and prosody), the time taken by the child to read a passage is recorded and the number of words that he/she can read per minute is computed. Furthermore, a 
The oral and silent reading ability of grade seven students of Calamba Bayside Integrated School

qualitative description of the child's manner of reading is described via a checklist. Finally, test taker's comprehension skills (the ability to create meaning) may be gauged by having the child answer five to eight questions of varying difficulty based on the graded passage after it has been read.

The Phil-IRI Silent Reading Test can be administered after the Oral Reading Test is conducted to further check the student's comprehension skill. When used to assess Silent Reading Comprehension, Phil-IRI may be used to describe reading speed and comprehension. The student's reading speed is measured by recording the time it takes the child to read each passage completely. Silent reading comprehension is measured by asking the student to answer five to eight questions of varying difficulty after a passage has been read. The Silent Reading Comprehension Test may be administered. The process of finding the independent, instructional, and frustration levels are the same except that the time it takes for the student to finish reading each passage is recorded by the test administrator. After each selection has been read, the test administrator reads the multiple choice questions that the student must respond to orally.

These two types of individual assessments (oral reading comprehension and silent reading comprehension), are aimed at finding the learner's independent, instructional, and frustration levels so that the teacher knows what level of reading materials the student can read and understand well, as well as what level of reading materials the student is not ready for.

The researcher would like to emphasize and reactivate the appreciation of reading so that the students would find reading coupled with their comprehension what they have read a pleasurable one. This is an activity which should be nurtured not only by the teacher but by themselves so that in the process of seeking for information, the students would have no difficulty reading, knowing the different strategies, approaches, and styles that motivate each student to go into reading according to the purpose he/she has in mind. With this, the student would not consider reading as a stressful and forced activity but a worthwhile and intellectual activity which can help him/her become a better reader and eventually become a tool to guide him/her to more complex activities in the future.

\subsection{Background of the study}

Understanding the significance of reading and in line with the implementation of the $\mathrm{K}$ to 12 Basic Education Program, the Department of Education (DepEd) implemented "Every Child A Reader Program" (ECARP) through DepEd Memorandum No.402.s.2004 and Administrative Order No. 324 (Gillaco, 2014). This aims to teach public elementary pupils with planned training in reading and writing to make them independent young readers and writers. Moreover, ECARP is also part of the ten-point education agenda of former President Simeon Benigno Aquino III to ensure that the country's public schools produce well-equipped graduates who could cope with the different challenges in life.

Despite the intensification of educational reading programs in public schools, there are still low performing students and some have very little improvement in their performances. The demand for English proficiency through reading among students is rising. Despite the students' mastery of the basic elements of English such as grammar and vocabulary, their reading comprehension levels still need improvement. In fact, in the latest Program for International Student Assessment (PISA) report, among 79 participating countries and economies, the Philippines scored the lowest in reading comprehension in 2018. PISA is a worldwide study by the Organization for Economic Co-operation and Development that examines students' knowledge in reading, mathematics, and science. Reading was the main subject assessed among 15-year old students in the 2018 PISA. The Philippines had an average reading score of 340, more than 200 points below China (555) and more than 100 points less than the OECD average (487).

In the Philippines, the students' performance in reading ranked lowest among PISA-participating countries. "Reading proficiency is essential for a wide variety of human activities - from following instructions in a manual to finding out the who, what, when, where, and why of an event to communicating with others for a specific 
purpose or transaction", the summary of the PISA 2018 results reads (San Juan, 2019). According to the PISA 2018 profile of the Philippines, socio-economic status accounts for $18 \%$ of the variance in reading performance in the country, compared to the OECD average of $12 \%$. The country has the largest percentage of low performers in reading among socio-economically disadvantaged students. The profile noted that the average class sizes of 15-year olds in the Philippines are the largest, and the ratio of students to teaching staff in socio-economically disadvantaged schools is the highest.

The Philippines also had the highest percentage of students reporting being bullied at least a few times a month. Education Secretary Leonor Briones said they did not expect high marks based on the National Achievement Test results (San Juan, 2019). As a Junior high school teacher, the researcher has also observed the same reading difficulties among high school students of the school she is connected with. Observing the reading problems encountered by teachers in reading and having been inspired to rectify these difficulties for students who struggle to read, the researcher decided to work on the current study.

Rating a student's ability is done in two ways: by identifying the student's miscues in oral reading; while in silent reading, comprehension is rated through answering questions right after the oral reading to find out how well a student understood the read passage. Based on the standard set by the PHIL-IRI, scores in word reading and comprehension categorize the readers into 3 levels: frustration, instructional, and independent. Hence, this study was conceived to make use of the Phil-IRI to determine the oral and silent reading ability level in English of the Grade seven students in Calamba Bayside Integrated School enrolled during the S.Y. 2019-2020.

\subsection{Theoretical framework}

This research study is anchored on the schema theory that influences comprehension in reading. According to Espejo et al. (2016) in an article written and published in The Normal Lights, this theory advocates that schema is a knowledge structure. It is based on the pre-text and notion that an individual possesses stored knowledge or long-term memory which enriches experience - a systematic personal organization of the individual's total experience. How the reader makes sense of incoming information is influenced by what the reader knows. Certain functions of schema as it relates to reading comprehension are identified as follows: it provides framework in organizing information read, it permits selective attention, and it permits inferential thinking. In this study, the role of the child as a reader is to assimilate information gathered through reading in three (3) sample categories: Literal comprehension (reading the lines), Inferential comprehension (reading between the lines), and (3) Critical comprehension (reading beyond the lines). In relation to this study, Gray (1950 as cited by Hingpit, 2014) described reading as a four-step process: perception of word, comprehension of its meaning, reaction to the meaning in terms of what one knows, and integration of the idea into one's background of experience.

The four parts of the circle show reading as a four-step thinking process of perception, comprehension, reaction, and integration. The cognitive process also includes interpretive or creative reading in a word recognition sequencing process. The linguistic process includes the syntactic, semantic, and meaning (deep structure) in decoding encoding print into meaningful concepts. The affective processes are interactions of self-concept, attitudes, and anxieties. All of these affect a reader's facility in assimilating ideas through written language, which is his speed of comprehension in reading.

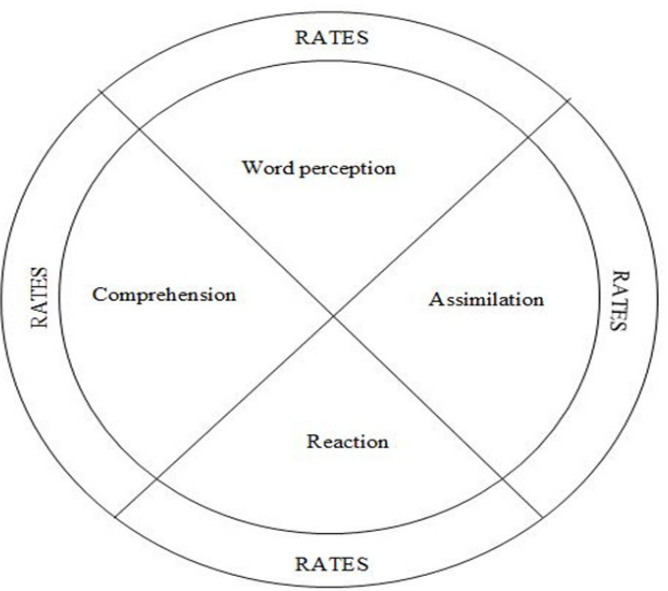

Fig. 1 Operational Model of the Reading Process 
The oral and silent reading ability of grade seven students of Calamba Bayside Integrated School

Word perception involves sensation. The eyes see the printed symbols with the aid of light rays that strike the retina. They move together in a swift and well-coordinated way making a series of fixations, jumping from word to word. It is when the eyes pause or rest that one actually reads. The distance or the number of words between fixation points is called the span of perception or recognition span. A good reader makes few fixations and few regressions or backward movements. Thus, his perception span is much longer than that of a poor reader.

Word perception also involves the identification of the printed symbol and the meaning that the author had in mind. For example, one identifies the combination of letters c-a-t as cat and not cot or cut. The printed word then acts as a trigger to release a meaning which the reader already possesses. To do this task, referred to as the decoding process, certain skills are required. These are the ability to: use sight vocabulary and configuration memory, use context clues to determine pronunciation and meaning, and determine pronunciation and meaning through structural analysis. This mean analysis of word structure is according to its parts; roots, affixes, inflected, and derived forms. It also includes the ability to relate the sound of the spoken word to its visual or grapheme symbol, referred to as phonic analysis, and use a dictionary to determine pronunciation and meaning of words resistant to analysis through the use of other skills.

Comprehension of ideas requires the fusion of meaning of separate words into a chain of related ideas. Initially, one reads to understand what the passage says in its main ideas, specific facts and details, sequence, directions to be followed, etc. Later, the implied level which involves drawing inferences, sensing relationships, drawing conclusions, and recognizing the author's purpose, tone, and feelings helps one to understand the total meaning of the passage.

Reaction includes the ability to judge accuracy, quality, or worth. These judgments are the results of critical reading and experience. On the emotional level, reaction requires value judgments, experience, background, and the ability to recreate sensory images. Reaction occurs only when comprehension is fully realized. One's reaction is affected by culture which controls the quality and quantity of experience available to the reader. Thus, experience becomes the foundation stone of the reading process.

Assimilation/Integration is determined by the reaction of the reader. If ideas are accepted, they become a part of his total experience. They are assimilated/integrated with all previous related experience. On the other hand, wrong concepts are corrected, and new insights are acquired. Integration also involves applying ideas acquired in problem solving. Rates refer to the speed of recognition, comprehension, reaction, and assimilation. Rates are flexible. They vary according to the reader's purpose and the difficulty of the material.

The PASS theory, according to Panayiota et al. (2016), proposes that cognition is organized in four processes and that these processes are functions of four areas of the brain. The first process is Planning, which involves executive functions responsible for controlling, organizing, and monitoring behavior. For example, shifting attention during reading to different parts of the text and selectively allocating resources and effort to different information are involved in this kind of processing. The second process is Attention, which ensures sufficient arousal levels and focuses on specific stimuli. For example, performance in selective attention and reading comprehension tasks is likely to be related when there is a need to inhibit stimuli that are not the primary focus of attention (e.g., when a word or a sentence is degraded or masked by non-targets in the surrounding). The other two processes, Simultaneous and Successive processing, enable encoding, transformation, and retention of information. Simultaneous processing is relevant when the task or behavior requires integration into whole units of information, or a "gestalt." For example, recognition of whole words by sight involves this kind of processing, as does comprehension of the meaning of an entire sentence in a paragraph. Successive processing is relevant when the task or behavior requires organization of individual units in a serial order. For example, word decoding, and spelling are involved in this kind of processing. Even though intelligence, when assessed with traditional IQ tests, only weakly relates to reading achievement; while intelligence, when assessed in terms of cognitive processes, relates strongly to reading achievement (Georgiou \& Das, 2012; Naglieri \& Reardon, 1993). 


\subsection{Statement of the problem}

This study aimed to determine the oral and silent reading ability level in English of Grade seven students. It also sought to answer the following questions.

$>\quad$ What is the oral reading ability level of the grade seven students in English using the Phil-IRI based on the following set of criteria: fluency; and comprehension level?

$>\quad$ What is the silent reading ability level of the grade seven students in terms of the following: fluency; and comprehension level?

$>\quad$ Is there a significant difference between the oral and silent reading ability of Grade seven students?

$>\quad$ Based on the results of the study, what enhancement program may be proposed to improve the reading ability of grade seven students?

\section{Literature review}

\subsection{Oral Reading Ability}

Fluency - According to Lysenko et al. (2014), reading is very important and has been linked to school achievement, graduation rates, and a country's overall economic success. Many children struggle with reading in today's schools. Estrada (2016) undertook a study on level of English Oral Reading Fluency among Abot - Alam secondary learners. He found out that the Abot -Alam secondary learners' over-all level of oral fluency in English is instructional. The result of the descriptive analysis shows that the overall mean score among the participants is 10.19 ( $\mathrm{SD}=2.340)$. The result reveals that the participants have instructional reading level in terms of accuracy, expression and volume, phrasing, smoothness, and pace. It is a notable result that students who were previously school dropouts were still able to read instructionally. This mirrors the effectiveness done by their former reading teachers and the present one as well in shaping them to become able readers who need less scaffolding. The text for them may be challenging but manageable. They were able to read with $90 \%$ precision even though there were a few times that they had to stop out of confusion on how to correctly read words. They managed to orally decode with a mixture of moderately fast and slow pacing, and with good prosody.

Robinson et al. (2016) stated that decoding refers to the process of translating a printed word into a sound. However, fostering skill in decoding is at the center of early reading instruction and represents one of the most important goals or academic instruction in the primary grades. Along this idea, Punsalan (2006 as cited by Estrada, 2016) believed that oral fluency is indeed very significant. When learners are frequently exposed to read-aloud, they learn context, pacing, inflection, pronunciation, the sheer beauty of language. They learn to visualize the story and begin to appreciate the power behind language used and expressed purposefully, cogently, and correctly. Fluency expands vocabulary development, context awareness, and recognition of audience, tone, purpose.

Likewise, Estrada (2016) stated that since oral fluency is crucial to the learners' success as readers, thinkers, leaders and employees in the near future, it is a huge responsibility for curriculum designers, administrators and reading teachers to not cease from giving them an environment that promotes the value of oral reading. At a micro level, the teachers must first inculcate the importance of listening to fluent oral reading. Teachers must model fluency by orally reading a text so learners can develop an internal sense of fluency. Other fluent readers can also be encouraged to read aloud. Secondly, proper assistance must be given to students who read in a non-fluent way.

On the other hand, Grant (2019) said that it may have a reader who can decode but cannot comprehend or 
The oral and silent reading ability of grade seven students of Calamba Bayside Integrated School

understand what they are reading. It is also possible to have a reader who can comprehend and decode but those oral reading is poor. The reader may orally read very slowly, mispronounce many of the words or read in monotone without expression. This type of reader has problems with fluency. The National Reading Panel Report (2000) defines oral reading fluency as the ability to read text with speed, accuracy, and proper expression. It is a level of accuracy and rate where decoding is relatively effortless, oral reading is smooth and accurate with correct prosody, and attention can be allocated to comprehension. Specifically, oral fluency refers to the accuracy and rate at which students expressively read a grade level text.

According to Rasinski (2010 as cited by Estrada, 2016), oral fluency is multifaceted. Nonetheless, it is frequently described in studies as having three major dimensions: (1) word reading accuracy, (2) automaticity or word reading rate or pace, and (3) prosody. Word reading accuracy requires readers to sound out the words in a text with negligible errors. This dimension refers to phonics skills and other strategies for decoding words. Automaticity, on the other hand, refers to instant processing of texts. The theory of automatic information processing in reading by La Berge et al. (1974 as cited by Estrada, 2016) argued that the surface- level processing of words in reading involving visual perception, sounding, phrasing words together, etc. must ideally be done at an automatic level, one which requires least attention or cognitive capacity. In so doing, readers can reserve their finite cognitive resources for meaning making - comprehension. Prosody, the third major dimension of oral fluency, is the appropriate use of phrasing and expression to convey meaning to the words implied through emphasis, and intonation. It is the capacity to make oral reading sound like spoken language. Rasinski (2010 as cited by Estrada, 2016) believed that when readers read easily and accurately but without expression in their voices, when they place equal emphasis on every word but have no sense of phrasing, and when they ignore most punctuation, then it is unlikely that they will fully understand the text.

Ankrum et al. (2014) employed a single case study to describe the nature of one teacher's verbal scaffolding used during differentiated reading instruction in a kindergarten classroom. The teacher participant was selected from a group of exemplary teachers nominated from two school districts in Southwestern Pennsylvania. Multiple sources of data, including transcripts of videotaped small group literacy lessons, were analyzed to glean insight regarding the nature of verbal scaffolding in classroom instruction. Transcripts were coded to identify salient patterns and themes related to lesson differentiation. The following categories were used to define the different types of talk used by the teacher to promote the independent use of strategies in reading: direct explanation, explicit modeling, invitations to participate, clarification, verification, and telling. Excerpts from transcripts were provided to illustrate examples of the different verbal scaffolds observed during the study. The teacher participant in this case study provided one example of how intentional verbal scaffolding can be used in early literacy instruction. Findings suggested that it may have positive implications for student literacy growth. Furthermore, the study offered rich descriptions of verbal scaffolding and quality examples of differentiated instruction that can support pre-service teachers and in-service teachers as they plan for effective literacy instruction.

Foorman et al. (2016) quipped that the most commonly used strategy to improve reading fluency is the reading and rereading of familiar texts. Opportunities to read aloud, with guidance from teachers, peers or parents, are also associated with the development of fluent reading. The Education Endowment Foundation (2017) specifically recommended that guided oral reading (where the teacher models fluent reading of text, then the pupil reads the same text aloud, with appropriate feedback. Repeated readings- where students read and reread a short and meaningful passage a set number of times or until they reach a suitable level of fluency.

Furthermore, the reader's oral fluency and over-all reading proficiency level can be independent, instructional, or frustration. The University of Utah Reading Clinic (2015) describes frustration level, the lowest level, as that which requires extensive assistance from an educator. It is when the passage is too difficult for a learner to read, and little or no learning will take place. The instructional level is one at which the text can be read by the learner, but with some teacher guidance and instruction to aid content comprehension. This is the level where readers have adequate background knowledge for a topic, and can access text quickly and with no or 
few errors. This is the most important level where learning rightly transpires. The independent level is one at which a learner can read the passage comfortably and easily and without any teacher assistance or guidance at all.

Word Recognition refers to the ability to identify a written word by sight or by deciphering the relationship between the sounds of spoken language and the letters in written language. If there is difficulty in word recognition in reading a particular selection, there is going to be a gap in the understanding of the text. This gap will post a problem in the readers' comprehension of the selection (Phil-IRI Manual of Administration, 2018). Word recognition accuracy and automaticity are the foundation for fluency. According to Snowling (2014), many struggling readers have phonological processing difficulties and there is evidence that skilled readers access a store of words or visual patterns when reading. High frequency words are words that occur frequently in text, for example the, what, this. Automatic recognition of these words (also called having a sight vocabulary) helps students to improve fluency, it also allows them to make use of context clues and focus more on comprehension than on decoding. Many high frequency words have irregular spelling patterns and sounding out these words can be pointless and frustrating.

There are seven (7) reading miscues identified in the Phil-IRI Oral Reading Test which is conducted twice (pretest and posttest) annually to determine the reading profile of pupils at the start and end of the school year, respectively. While the oral reading test is conducted, the teacher is recording the miscues (errors) committed by the pupils individually to identify the strengths and weaknesses of each child. Teachers believe that through identification of common reading errors, they will be able to come up with an organized unified reading intervention to address the reading difficulties of pupils.

The following are the identified reading errors in oral reading: Mispronunciation - is a reading miscue where the pupil attempts to pronounce the word, but produces a nonsense word, rather than a real one; Substitution - is a reading miscue where the pupil substitutes a real word that is incorrect; Insertion - a reading miscue where the pupil inserts a word or a series of words that does not appear in the text; Omission - is a reading miscue where the pupil omits a word or a continuous sequence of words in the text but continues to read; Repetition - is a reading miscue where the pupil repeats one or more words that have been read. Groups of adjacent words that are repeated count as one repetition; Reversal - is a reading miscue where the pupil reverses the order of words or letters; and Refusal to Pronounce - is a reading miscue where the pupil neither pronounces the word nor attempts to do so. The teacher pronounces the word so that testing can continue (Phil-IRI Manual of Administration, 2018).

Comprehension - Head et al. (2014) stated in his article that generally, learners experiencing defecate in reading comprehension have inadequate oral language proficiency owing to limited lexical, syntactic and semantic knowledge. He underscores that new vocabulary acquisition enhances reading comprehension, and also requires well-linked knowledge of phonological and orthographic word forms in addition to well-developed syntactic and semantic memory associations. Moreover, Paz (2018) conducted a study on reading comprehension levels in English among grade seven students in Caraga State University. He assessed the respondents' reading comprehension levels. The study recommended that English teachers should consider programs and activities in school that develop students' critical and interpretive thinking, and conduct regular evaluation to monitor their academic progress in reading comprehension.

Also, Cabardo's (2014) research study, majority of the students belonged to frustration level of reading proficiency in silent reading while in instructional level for the oral reading. He found out that there is a significant difference on the levels of reading proficiency of students in silent and oral reading. According to Denton, et.al. (2011 as cited by Nasibog et al., 2016), learners can comprehend well the information they have read if they read it orally as compared to silent reading. It was expound by other researcher that when learners read orally the process of their reading will allow to bound the understanding or comprehending of what they have read because they might focus on how the pronunciation, intonation and how they are going to read the 
The oral and silent reading ability of grade seven students of Calamba Bayside Integrated School

words correctly. It was also stated that when fluent readers can help their self and the low readers to improve their reading pronunciation and other through listening. On the other hand, assessment in oral reading fluency is said to be the indicator of reading comprehension according to past studies, it was claim in some research that oral reading fluency (ORF) is approve as effective assessment that being used in elementary student in terms of their reading competence.

Along this idea, Westby (2012 as cited by Rocero et al., 2014) said that successful comprehension requires coordination of skills at many levels to extract and construct meaning. The level of difficulty associated with comprehension of certain content depends on the complexity of the language used. There are important differences between the language that we use in everyday conversations and the language used in school, where everyday conversations are originally used to achieve daily tasks and share personal information. Academic language includes a different set of words, more complex grammatical structures and different text organization to express content which describes complex relationships. These two factors aforementioned have significant connection as how students comprehend in general.

\subsection{Silent Reading Ability}

Fluency - According to Estrada (2016), high school students are already expected to read fluently and accurately. He recommended in his study that the reading teacher should continue providing them with reading materials suitable for their needs and grade level and then move to more complex reading texts and those that actually cater to their areas of interest. These can provide avenues for the learners to grow from being a frustration reader to becoming an independent one. Amendum et al. (2017) reported a similar pattern in which variation in text complexity affects students' rate more than comprehension. Reading ability and text complexity are complementary, in that it is the difference between them that affects reading performance, another manifestation of the same phenomenon is that students who read with comprehension will read more slowly when texts are more complex.

Davis et al. (2016) determined the effective teaching practices in handling non-readers. Their study described the adjustments, effective strategies, and scaffolds utilized by teachers in handling non-readers; differentiated the teachers' reading adjustments, strategies and scaffolds in teaching non-readers; analyzed the teaching reading efficiency of non-readers using effective teaching reading strategies; and established significant correlation of non-readers' grades and reading teachers' reading adjustments, strategies and scaffolds. Results revealed that handling non-readers in order to read and understand better in the lesson is an arduous act, yet; once done with effectiveness and passion, it yielded a great amount of learning success. Also, effective teaching practices in handling non-readers comprised the use of teachers' adjustments, strategies, and scaffolds to establish reading mastery, exposing them to letter sounds, short stories, and the use of follow-up. Further, WH questions enhanced their reading performance significantly and variations of reading teachers' nature as an enabler, a facilitator, a humanist, a behaviorist, and an expert were noted.

Homer et al. (2014) argued that reading to young children has a number of benefits, including supporting the acquisition of vocabulary and literacy skills. Digital reading games, including ones with new modes of interface such as the Kinect for Xbox, may provide similar benefits in part by allowing dynamic in-game activities. However, these activities may also be distracting and detract from learning. Children (ages 5-7 years, $\mathrm{N}=39$ ) were randomly assigned to either i) jointly read a story with an adult, ii) have the story read by a character in a Kinect game, or iii) have the story read by a character in a Kinect game plus in-game activities. Both Kinect-Activities and Book Reading groups had significant gains for High Frequency Words, Active Decoding, and Total Reading Score, but only Kinect-Activities group had significant gain for Sight words. Overall, the findings are encouraging for the next generation of digital literacy games.

Alokan et al. (2013 as cited by Tibus, 2016) stated that there are two factors that affect learning: nature and nurture. The first determines the level of intelligence and the inherited abilities of the children while the latter 
facilitates to maximize these innate abilities. According to Fitzer et al. (2015), children can memorize words by sight instead of developing word attacking skills. This memorizing strategy allows children to guess at most words in the early grades from the initial letter or whole word configuration (shape of word) and still achieve average scores on most reading tests. Word recognition accuracy and automaticity are the foundation for fluency. In addition, Daniel (2014), in a large scale effort (approximately 8,500 fourth through eighth graders) aimed at creating a standardized measure of silent reading rate and comprehension, reported that the relationship between comprehension and rate was positive for the top $82 \%$ of the sample. Among poor comprehends (bottom 18\%), the relationship was inverse. The faster these students read, the poorer they comprehended.

On the contrary, Vorstius et al. (2014) have not considered the comprehension following reading in silent or oral reading context but using state-of-the-art eye tracking technology, they have studied eye movements of 605 students in Grades 1 through 5 reading orally and silently. Weaker comprehends were slower than stronger comprehends, especially in oral reading, and showed less flexibility in the allocation of word processing time. They speculated that the overall slowing of processing speed in oral reading was due to increased demands of processes such as speech planning, articulation monitoring, and eye-voice coordination-demands that are not present in silent reading contexts.

Then Rasinski et al. (2017) examined the impact of an intensive reading fluency intervention on the overall reading performance of 37 struggling readers in 3rd grade. Students' 3rd-grade classroom teachers and/or their performance on a state-mandated reading achievement test given toward the end of the 3rd-grade school year identified them for the study. Selected students participated in a 25 -session summer reading clinic. The main instructional intervention was the Fluency Development Lesson, which is an intensive fluency instruction program. Immediately prior to and after the summer reading program, clinicians conducted pre- and post-test to students on a variety of reading competencies.

Analyses of pre- and post-test scores showed that students who had received fluency instruction in the summer clinic made substantial and significant gains in their reading performance. This is noteworthy because despite the fact that many students actually lose ground in their reading achievement over summer, these students made significant reading performance gains. Correspondingly, Fitzer et al. (2015) stated that it is important to build vocabulary first and foremost, and then decoded words can be translated into reading sight words efficiently. With sight word recognition and reading speed, the demands on working memory are less, and so working memory can be used for reading comprehension to occur.

There are five components needed in reading and these are phonemic, phonetic, fluency, vocabulary and text comprehension. According to Cerado et al. (2018) these five components need to be integrated as children learn to read. For example, students who cannot recognize or decode written words cannot read fluently, or do not understand the meanings of words, will be limited in their text comprehension abilities. Reading meaningful texts at appropriate levels of difficulty is one way for children to increase their vocabulary and practice their phonics skills. To construct meaning from written texts, skilled readers bring together all the components of reading in combination with their prior knowledge about what they are reading.

Trainin et al. (2015) conducted a study on a comparison of reading rates, comprehension, and stamina in oral and silent reading of fourth-grade students. On his study, he examined the relationships between silent and oral reading fluency and comprehension. He found out that fourth grade students had consistent levels of comprehension in both reading modes. Students of all reading levels showed a similar pattern across the segments of a text set in both oral and silent reading. There is a gradual increase in rate from texts one through three, a drop-off on text four, and the fastest speed on text five. A portion of the sample engaged in abnormally rapid silent reading relative to their oral reading rates coupled with low comprehension.

The study recommended that federally funded reports and district mandates during the NCLB era may have encouraged many elementary teachers to emphasize oral reading to a greater extent than silent reading. There are reasons for oral reading in classroom settings at all levels, including high school ones, such as the sharing of 
The oral and silent reading ability of grade seven students of Calamba Bayside Integrated School

evidence from texts to justify answers to questions about content. But the findings of the study point to the need for more nuanced consideration of the role of silent reading in elementary students' school experiences.

Comprehension - The National Panel (2000 as cited by Nasibog, 2016) noted that reading comprehension in children or elementary students is the crucial stage to learn. For the students to attain the progress of their learning of children should recognized word, because if the student will not be able to comprehend learners may fall to be a good reader. Children must acquire basic skills in reading and must knowledgeable. It was claim that reading comprehension is the very basic factor of gaining knowledge. Students must not force to read but adore while reading a text, because there is a certain that student may not understand the text being read.

Tibus et al. (2016) made a study to investigate the reading comprehension ability of Grade VI Pupils of Tomas Oppus Central School. He stated that academic progress depends on understanding, analyzing, and applying the information gathered through reading. The lack of strong reading comprehension skills definitely affects a students' success in school. The best way to develop the comprehension ability is to expose children to reading in terms of both time and reading materials. The mind needs exercises in the process of digesting ideas and digging deeper into the meaning of things that it gets from reading. Constant reading sessions in school will definitely increase the reading comprehension skills of the pupils. Moreover, reading to them at an early age and asking thought-provoking questions after every reading session would very much likely increase their comprehension ability.

According to Fitzer et al. (2015), problems with long term visual memory can lead to poor sight word recognition. Without a good sight word vocabulary, reading speed is reduced, and working memory is consumed with reading decoding/attack. This does not allow for working memory to keep track of the words read, and comprehension is subsequently impaired. Also Miñoza et al. (2019) found out on her study that as the respondent increase in their age their level of silent reading comprehension becomes better. This implies that age is a factor influencing silent reading comprehension. It is noted that silent reading is a form of independent reading. Therefore, this type of reading is performed by learners without or with less supervision and assistance from their teacher, their parents or other supporting individuals. She claimed that learners are accumulating skills over the years and it varies according to different factors. It is pointed that in her study that as students' age and mature they can acquire certain skills. This explains the significant relationship of age with comprehension in silent reading. As the respondents' age, they can competently perform silent reading as an independent task.

The Philippine Informal Reading Test or Phil-IRI (2018) delineates that reading is a complex process that includes phonemic awareness, phonic, reading fluency, and reading comprehension. Moreover, it is the process of constructing meaning though dynamic interaction among the readers' existing knowledge, the information suggested by the text being read, and the context of the reading situation. While reading lies on the process, reading comprehension focuses on the level of understanding a text. This understanding comes from the interaction between the words that are written and how they trigger knowledge outside the text. Thus, fluency in reading and the ability to read with comprehension serve as the cornerstone of a child's success in school and later on throughout his life. Viewed as a basic skill, learning to read and understand what was read are integral part in the life of every individual and indispensable in the circle of educational system.

Reading comprehension is a skill that can be strengthened and improved through more reading practice. Pardo (2014) stated that increasing vocabulary, extensive reading and critical reading are some of the practices that can be used to strengthen and refine the person's ability to comprehend any text. An individual ability to comprehend text is influenced by their traits and skills. If word recognition is difficult, students use too much of their processing capacity to read individual words, which interferes with their ability to comprehend what is read. There are number of approaches to improve reading comprehension, including improving one's vocabulary and reading strategies. This understanding comes from the interaction between the words that are written and how they trigger knowledge outside the text/message.

Betty et al. (2009) defined comprehension as a mental process aimed at extracting the meaning from the 
written, audio or visual source and integrating it into the cognitive structure of the recipient. Comprehension is one of the major thought processes, where its tools are represented in silent reading, listening and viewing. when it is applied to reading, it means that the good reader activates his mental schemes on the subject and builds his assumptions about the content then he/she reads to prove, deny or modify those expectations where he/she uses this ability to identify letters, words, know the semantics, rules of sentence structure, other language knowledge and the characteristics of literary genres and patterns besides his /her general knowledge and culture. That's contradicted to what was proposed by the supporters of transformational generative theory who described comprehension as building up the meaning from simplest forms of language which is sentence. To extract and comprehend the meaning from text, the reader uses some cognitive and meta-cognitive strategies as this requires the clarity of vocabulary and knowledge of the world that surrounds the reader. This extraction means to identify and understand the information and ideas contained in the text. Or it means to rebuild the meaning by interpreting the text and making Inferences based on what the personal experiences that the reader has.

According to the views of language teachers, Neff et al. (1999), in this period, the learning to read does not exceed the level of translation of language written units and symbols into spoken sounds. Decoding of language symbols process is considered as one of the assisting skills in the formation of reading comprehension where that process is an easy way that does not consume the effort of the reader. Along this idea, Chen (2009) stated that if the children do a great effort to identify the words and letters, this will reduce their mind energy for the process of comprehension. In other words, the school should contribute in strengthening those initial skills to have children engaged in language symbols decoding process for the purpose of comprehension. School's failure to build basic reading skills and related knowledge leads to have a reader suffers from weakness throughout the duration of the school.

Habibian et al. (2014) argued that lack of reading comprehension skill leads to the failure in understanding information and ultimately results in poor academic performance. This is because comprehension is an interrelated skill involving a number of processes at several different levels. Consequently, difficulties in any one of several component skills may contribute to comprehension failure. While Gilakjani et al. (2016) stated that reading comprehension, on the other hand, is a significant skill that furthers the development of learners' various academic tasks. It helps them decoding a text, analyzing, explaining, and expressing their own ideas about written materials. Learners should develop a strong ability to understand written materials to struggle with the academic tasks that their teachers deal with them. A primary objective of reading comprehension is to aid learners improve skills and comprehension of texts if they want to be skilled readers.

In the article published online by Graham et al. (2015), learners with learning disabilities often experience poor comprehension due to their failure to read strategically and to spontaneously monitor their understanding while reading. These are the learners who on testing don't present with language disorder, but have a low ability in key language areas, such as grammar, syntax and perhaps most importantly, vocabulary knowledge. It's important to understand that for a child to adequately comprehend an author's written message it requires them to be able to analyze and sort through multiple layers of text meaning. Research indicates that children with reading comprehension problems have poor inference skills. Poor inference skills could result from poor background knowledge, weak vocabulary and semantic word knowledge, and incomplete knowledge of story grammar and prediction. In addition, there is reliable evidence that reading comprehension difficulty occurs frequently in children who are actually good decoders and spellers (Cicerchia, 2016).

Fitzer et al. (2015) believed that vocabulary is the glue that holds communication and comprehension together, making them accessible for children. These are four categories of learners for whom vocabulary acquisition and instruction are most challenging: learners with limited or no knowledge of English, learners who do not read outside of school, learners with reading or learning abilities, and learners who enter school with limited vocabulary knowledge. In like manner, Alphonse et al. (2014) stated that two of the most studied approaches for developing learners' reading comprehension skills are teaching vocabulary and teaching reading strategies. Additionally, Head et al. (2014) averred that educators can best support learners by integrating the 
The oral and silent reading ability of grade seven students of Calamba Bayside Integrated School

teaching of the vocabulary with the teaching of the reading comprehension strategies. The goal of the vocabulary is to facilitate learners' ability to interact with language situations, primarily in the understanding text.

\subsection{Synthesis}

The related literature and studies cited had similarities and differences to the present study in the sense that they all dealt with reading comprehension. Some of them discussed the respondents' level of reading comprehension. The present study is related to the studies of Estrada. He assessed the English oral reading fluency of the learners and found out that the participants had instructional reading level in terms of accuracy, expression and volume, phrasing, smoothness, and pace. Foorman, Education Endowment Foundation, and Homer suggested that the most commonly used strategy to improved reading fluency is the reading and rereading of familiar texts. However, in the study of Grant, National Panel, Amendum, and Snowling, they reported that it may have readers who can decode but cannot comprehend or understand what they are reading. It is also possible to have readers who can comprehend and decode but their oral reading is poor.

Word recognition accuracy and automaticity are the foundation for reading fluency. In the studies of Estrada, Cabardo, and Trainin, they identified the reading miscues of the respondents such as mispronunciation, substitution, insertion, omission, repetition, reversal, and refusal to pronounce. The studies of Fitzer et al., Foorman et al., Pardo, Habibian, et al., and Gilakjani et al., all dealt with reading comprehension ability of the students. There are number of approaches to improve reading comprehension, including improving one's vocabulary and reading strategies. They claimed that the best way to develop the comprehension ability is to expose children to reading in terms of both time and reading materials. To Davis, handling the non-readers in order to read and understand the lesson better, was an arduous act, yet once done with effectiveness and passion, it yielded a great amount of learning success.

On the other hand, in the study of Paz and Cabardo, they assessed the respondents' reading comprehension level in both silent and oral using the Phil - IRI materials. They found out that majority of the respondents were under the frustration level and there was a significant difference on the levels of reading proficiency of students in silent and oral. They both recommended that it is crucial that learners are taught the importance of getting meaning from reading materials. The studies of Daniel, Miñoza, et al., Vorstius et al., Foorman et al., and Education Endowment Foundation were somewhat similar to the present study as all of these studies determined the reading proficiency level of high school students in silent reading. They found out that as the respondents increased in their age, their level of silent reading comprehension became better. They claimed that learners accumulated skills over the years which varied according to different adding factors. They believed that the most commonly-used strategy to improved reading fluency is the reading and rereading of familiar texts.

\section{Method}

Design - The study used the descriptive method of research design considering that the goal of the study was to determine the oral and silent reading ability level of the grade seven students. It is descriptive in design because it presented in narrative form the data gathered on the selected sample of respondents and the administered questionnaire. The method was utilized to describe the data for variables investigated to ascertain the condition in teaching reading.

Locale of the study - This research investigation was conducted at Calamba Bayside Integrated School in Brgy. Palingon, Calamba City Division. Calamba City is located in the province of Laguna, Region IV-A CALABARZON. The researcher chose the school where she currently teaches.

Participants - The researcher employed the G power sampling method in selecting samples for the study. To give fairness and chances to others, drawing of lots was used. Each student was asked to draw from the box a properly folded piece of paper. On some of these pieces of paper were numerals needed to determine the participants for the test. All students who drew out a number were asked to participate in the test. A total of 150 
students participated the study.

Instrumentation and validation - This study used the Philippine-Informal Reading Inventory (Phil-IRI) materials in assessing the oral and silent reading ability of the students. The Graded Passages in grade 7 were expository texts. The expository texts in English focused on Science concepts. The computation of the oral reading score involved counting the number of miscues during oral reading. Each miscue carried equal weight, regardless of whether it affected the meaning of the passage or not.

The Phil-IRI-Silent Reading Test gives quantitative information about the pupil's silent reading capabilities. Quantitative information shows the reading levels, namely: frustration, instructional, and independent. Furthermore, it uses predetermined set of criteria in identifying the reading levels of the pupils such as the reading speed and percentage of correct answers to comprehension questions. It has adapted the combination of bands of reading rate (words per minute) proposed by DepEd Manual 2018. In this study, the level of reading proficiency was interpreted based on the result of the computation. The Manual of Phil-IRI Test Administration and Interpretation which was retrieved from the DepEd Calamba City Division was used as the main reference in the interpretation.

The following is the interpretation of word reading and comprehension level of each student for each passage:

\section{Table A}

Interpretation of word reading and comprehension level

\begin{tabular}{ccc}
\hline Oral Reading Level & Word Reading Score(in \%) & Comprehension Score(in \%) \\
\hline Independent Level & $97-100 \%$ & $80-100 \%$ \\
Instructional Level & $90-96 \%$ & $59-79 \%$ \\
Frustration Level & $89 \%$ and below & $58 \%$ and below \\
\hline
\end{tabular}

The student's word reading score and comprehension score were taken together to determine a comprehensive reading profile for that passage. A description of the student's reading profile in word reading and comprehension per passage is presented below:

\section{Table B}

Student's reading profile in word reading and comprehension per passage

\begin{tabular}{ccc}
\hline Word Reading & Reading Comprehension & Reading Profile per passage \\
\hline Independent & Independent & Independent \\
Independent & Instructional & Instructional \\
Independent & Frustration & Frustration \\
Instructional & Independent & Independent \\
Instructional & Instructional & Instructional \\
Instructional & Frustration & Frustration \\
Frustration & Independent & Frustration \\
Frustration & Instructional & Frustration \\
Frustration & Frustration & Frustration \\
\hline
\end{tabular}

Data gathering procedure - The researcher prepared letters addressed to the head of school asking permission to conduct the research. After the consent was given, the researcher immediately began the administration of the research instruments, particularly the survey questionnaires. The researcher personally distributed the instrument to the respondents. During the distribution of the instrument, the researcher explained the mechanics and translated the statements into the vernacular in order to elicit the information needed by the study. The results were statistically treated using appropriate statistical tools with the aid of an accredited statistician. A maximum of 30 minutes a day at a time for each type of assessment was given. Every student was asked to read the predetermined selection for the particular grade level from the Phil-IRI book prescribed by Department of Education. After reading, they were requested to answer the questions that followed the passage. 
The oral and silent reading ability of grade seven students of Calamba Bayside Integrated School

Their responses were recorded simultaneously to have a basis for labeling the level of comprehension pre-determined by DepEd.

Ethical consideration - As the study required participation of Grade seven students, ethical issues were addressed. The consideration of these issues is necessary to ensure the privacy and security of participants. Issues of confidentiality and anonymity, right to conduct an investigation, and securing free and informed consent from respondents were the ethical issues which emanated in conducting this research since it determined the oral and silent reading ability level of the respondents. However, these issues were prevented by securing legal permission from concerned authorities and concrete explanation of the benefits which would be derived from the results of the study. The confidentiality of the respondents' information was ensured by not disclosing their names and the section to which they used to belong. Only relevant information needed to answer the specific research questions were included in the study.

Treatment of data - The data to be gathered from the questionnaires were collected, tallied, and treated using the following statistical techniques. To answer problem numbers 1 and 2 on oral and silent reading ability of grade seven students in English using the Phil-IRI in terms of fluency, the reading speed formula was applied. The reading speed was computed by dividing the total number of the words in the reading passage which was 152 by the reading time in seconds then multiplying it by sixty.

Table C

Criteria for reading speed

\begin{tabular}{ccc}
\hline FAST & AVERAGE & SLOW \\
\hline 190 and above & $161-189$ & 160 and below \\
\hline
\end{tabular}

The table above was used as the basis for the reading speed of grade 7 students. It shows that a student's reading rate of 190 and above words per minute was considered fast; while 161-189 was average; and 160 and below was slow.

\section{Table D}

Percentage for comprehension scores

\begin{tabular}{ccc}
\hline No. of Items & Score in Comprehension & $\%$ \\
\hline 8 & 8 & 100 \\
7 & 88 \\
6 & 75 \\
5 & 63 \\
4 & 50 \\
3 & 38 \\
2 & 25 \\
1 & 13 \\
\hline
\end{tabular}

The table above was used as the basis for the reading comprehension of grade 7 students. A student who reached $80-100 \%$ was considered under the Independent level; while 59- 79\% was under the Instructional level; and $58 \%$ and below was considered to be in the Frustration level. To answer problem number 3 , $\mathrm{t}$ - test was used in order to find out if there was a significant difference in the oral and silent reading ability of the grade seven students when classified using the Phil - IRI. The percentage of the number of miscues with the total number of graded passage was computed. The number of miscues was the number of a student's mispronounced words. It was needed to find out how many words were pronounced properly.

The following tables are basis for interpreting the individual reading profile of the participants form the Philippine Informal Reading Inventory (Phil-IRI). The table was the basis for interpreting the scores garnered by the students from the word recognition (oral reading) and the reading comprehension (silent reading). Once the scores were interpreted, the table below was referred to identify the oral reading level of the students. 
Dela Cruz, R. L., \& Recillo, M. L. B.

Table E

Criteria for word recognition and comprehension (adapted from Phil-IRI)

\begin{tabular}{ccc}
\hline Reading Ability Level & Word Recognition & Comprehension \\
\hline Independent & $97-100$ & $80-100$ \\
Instructional & $90-96$ & $59-79$ \\
Frustration & $89-$ below & $58-$ below \\
\hline
\end{tabular}

\section{Table F}

Criteria for oral reading (adapted from Phil-IRI)

\begin{tabular}{ccc}
\hline Word Recognition & Reading Comprehension & Reading Profile per passage \\
\hline Independent & Independent & Independent \\
Independent & Instructional & Instructional \\
Independent & Frustration & Frustration \\
Instructional & Independent & Independent \\
Instructional & Instructional & Instructional \\
Instructional & Frustration & Frustration \\
Frustration & Independent & Frustration \\
Frustration & Instructional & Frustration \\
Frustration & Frustration & Frustration \\
\hline
\end{tabular}

A learner's word recognition and comprehension score were taken together to determine his/her oral reading level. A description of a student's oral reading level in word recognition and comprehension in passage is presented above. If the set of participants is Independent in word recognition and Independent also in comprehension, then the participants are considered Independent; while if the set of participants is Independent in word recognition and instructional in comprehension, the participants are considered to be in the Instructional level and so on.

Table G

Criteria for silent reading (adapted from Phil - IRI)

\begin{tabular}{ccc}
\hline Reading Speed & Reading comprehension & Reading Level \\
\hline Fast & Independent & Independent \\
Fast & Instructional & Instructional \\
Fast & Frustration & Frustration \\
Average & Independent & Independent \\
Average & Instructional & Instructional \\
Average & Frustration & Frustration \\
Slow & Independent & Instructional \\
Slow & Instructional & Instructional \\
Slow & Frustration & Frustration \\
\hline
\end{tabular}

A learner's reading speed and comprehension score were taken together to determine his/her silent reading level. A description of the student's silent reading level in reading speed and comprehension in passage is presented above. If the set of participants is fast in reading speed and independent also in comprehension, then the participants are under the Independent level; while if the set of participants is fast in reading speed and instructional in comprehension, the participants are considered to be under the Instructional level and so on.

\section{Results and discussions}

Problem Number 1: The oral reading ability level of the Grade Seven students in English using the Phil-IRI based criteria in terms of:

Fluency Level - Fluency is the ability to read orally with speed. In this study, it involved the time the reader started reading the passage until the time he/she ended reading. According to the Phil-IRI guidelines, Grade VII 
The oral and silent reading ability of grade seven students of Calamba Bayside Integrated School

students are expected to read 161-189 words in a minute, which is considered an average reading speed for their level.

\section{Table 1.1}

Oral Reading Ability Level of the Grade 7 Students in English in Terms of Fluency

\begin{tabular}{|c|c|c|c|}
\hline Indicators & & Frequency & Percent \\
\hline Frustration & & 149 & 99.3 \\
\hline Instructional & & 1 & .7 \\
\hline \multirow[t]{2}{*}{ Total } & & 150 & 100.0 \\
\hline & Overall & 1.006 Frustration & \\
\hline
\end{tabular}

Table 1.1 shows the oral reading ability level of the grade seven students in English using the Phil-IRI-based guidelines in terms of Fluency. The overall oral ability of the grade seven is 1.006 which is interpreted as at the level of Frustration. There were 149 (99.3\%) students included in this level. Only one grade seven student was in the Instructional level. The results imply that most of the students did not reach the average level for reading speed and they were considered slow in oral reading. Participants were able to read but there were times that they had to stop. They hardly decoded words and their oral reading was halted from time to time which caused an extension in their reading time.

Estrada (2016) stated that since oral fluency is crucial to the learners' success as readers, thinkers, leaders, and employees in the near future, it is a huge responsibility for curriculum designers, administrators, and reading teachers to not cease from giving them an environment that promotes the value of oral reading. At a micro level, the teachers must first inculcate the importance of listening to fluent oral reading. Teachers must model fluency by orally reading a text so learners can develop an internal sense of fluency. Other fluent readers can also be encouraged to read aloud. Secondly, proper assistance must be given to students who read in a non-fluent way.

Along this idea, Punsalan (2006 as cited by Estrada, 2016) believed that oral fluency is indeed very significant. When learners are frequently exposed to read aloud, they learn context, pacing, inflection, pronunciation, and the sheer beauty of language. They learn to visualize the story and begin to appreciate the power behind language used and expressed purposefully, cogently, and correctly. Fluency expands vocabulary development, context awareness, and recognition of audience, tone, and purpose.

Comprehension Level - Table 1.2 shows the oral reading ability level of the grade seven students in English using the Phil-IRI - based guidelines in terms of Comprehension.

\section{Table 1.2}

Oral Reading Ability Level of the Grade 7 Students in English in Terms of Comprehension

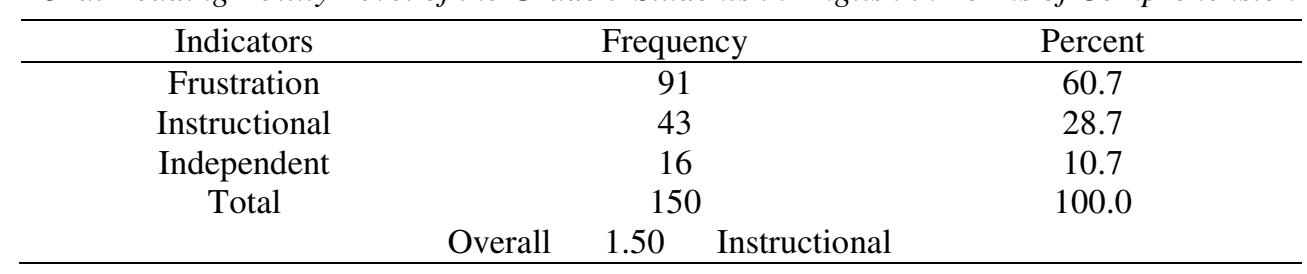

Table 1.2 shows the oral reading ability level of the grade seven students in English using the Phil-IRI based guidelines in terms of Comprehension. The overall oral ability of the grade seven students is 1.50 and interpreted as at the level of Instructional. There were $91(60.7 \%)$ who were found to be in the Frustration level, $43(28.7 \%)$ in the Instructional level, and $16(10.7 \%)$ in the Independent level. The results imply that the students comprehended the expository reading inventory with good comprehension level and good accuracy in word recognition. This is the level where students make the most progress in reading but they can read only with the support of the teacher or some assistance is given. The results indicate that the participants should be required to improve on this skill more to be in the independent level in comprehension. 
Similar to the study, Paz (2018) conducted a study on reading comprehension levels in English among grade seven students in Caraga State University. The study recommended that English teachers should consider programs and activities in school that develop students' critical and interpretive thinking, and conduct regular evaluation to monitor their academic progress in reading comprehension. According to Westby (2012 as cited by Rocero et al., 2014), successful comprehension requires coordination of skills at many levels to extract and construct meaning. The level of difficulty associated with comprehension of certain content depends on the complexity of the language used. There are important differences between the language that people use in everyday conversations and the language used in school, where everyday conversations are originally used to achieve daily tasks and share personal information. Academic language includes a different set of words, more complex grammatical structures, and different text organization to express content which describes complex relationships. These two aforementioned factors have significant connection to how students comprehend in general.

Problem Number 2: Silent Reading Ability Level of the Grade Seven Students in terms of:

Fluency Level - Table 2.1 shows the silent reading ability level of the grade seven students in terms of Fluency.

Table 2.1

Silent Reading Ability Level of the Grade 7 Students in English in Terms of Fluency

\begin{tabular}{ccc}
\hline Indicators & Frequency & Percent \\
\hline Frustration & 121 & 80.7 \\
Instructional & 22 & 14.7 \\
Independent & 7 & 4.7 \\
Total & $150 \quad$ Frustration & 100.0 \\
& Overall & $1.24 \quad$ r \\
\hline
\end{tabular}

Table 2.1 shows the silent reading ability level of the grade seven students in English using the Phil-IRI based guidelines in terms of Fluency. The overall silent reading ability of the grade seven is 1.24 and interpreted as at the Frustration level. There were $121(80.7 \%)$ who belonged to the Frustration level, $22(14.7 \%)$ to Instructional, and $7(4.7 \%)$ to Independent. The results imply that a great number of the students did not reach the minimum level for reading speed and they were considered slow in silent reading. Slower reading generally indicates that a reader has to enlist a greater amount of cognitive resources to recognize words. It shows that participants are seldom given opportunities to read silently during their early years and were not taught how to read silently efficiently. There is a need for them to expose to reading materials to enhance their reading skills.

Estrada (2016) opined that High school students are already expected to read fluently and accurately. He recommended in his study that the reading teacher should continue providing them with reading materials suitable for their needs and grade level and then move to more complex reading texts and those that actually cater to their areas of interest. These can provide avenues for the learners to grow from being at the level of a frustration reader to becoming an independent one. According to Cerado et al. (2018), the five components of phonemic, phonetic, fluency, vocabulary, and text comprehension need to be integrated as children learn to read. For example, students who cannot recognize or decode written words cannot read fluently, or do not understand the meanings of words, will be limited in their text comprehension abilities. Reading meaningful texts at appropriate levels of difficulty is one way for children to increase their vocabulary and practice their phonics skills. To construct meaning from written texts, skilled readers bring together all the components of reading in combination with their prior knowledge about what they are reading.

Correspondingly, Fitzer et al. (2015) stated that it is important to build vocabulary first and foremost, and then decoded words can be translated into reading sight words efficiently. With sight word recognition and reading speed, the demands on working memory are less, and so working memory can be used for reading comprehension to occur. 
The oral and silent reading ability of grade seven students of Calamba Bayside Integrated School

Comprehension - Table 2.2 shows the silent reading ability level of the grade seven students in terms of Comprehension.

\section{Table 2.2}

Silent Reading Ability Level of the Grade 7 Students in Terms of Comprehension

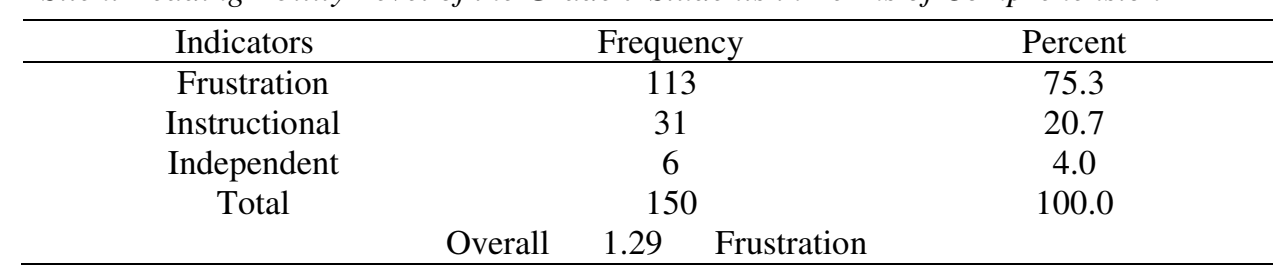

Table 2.2 shows the oral reading ability level of the grade seven students in English using the Phil-IRI-based guidelines in terms of Comprehension. The overall oral ability of the grade seven is 1.29 interpreted as at the Frustration level. There were $113(75.3 \%)$ who belonged to the Frustration level, 31 (20.7\%) to Instructional level, and $6(4.0 \%)$ to Independent level. The results were not what the researcher expected since she was cognizant of the skills of her students. Several barriers were considered for such results: before, the researcher as their English teacher used to give them a narrative text for their passage; But for this research, the researcher gave the students an expository text which was focused in science concepts. There was a degree of difficulty engaging the unfamiliar terms in their new passage. There were some terminologies which with the students were not familiar. This could only mean that the students had a limited vocabulary and they were not exposed to such printed materials in the early grades.

Reading comprehension is a skill that can be strengthened and improved through more reading practice. Pardo (2014) stated that increasing vocabulary, extensive reading, and critical reading are some of the practices that can be used to strengthen and refine the person's ability to comprehend any text. An individual's ability to comprehend text is influenced by his/her traits and skills. If word recognition is difficult, students use too much of their processing capacity to read individual words, which interferes with their ability to comprehend what is read. There are a number of approaches to improve reading comprehension including improving one's vocabulary and reading strategies. This understanding comes from the interaction between the words that are written and how they trigger knowledge outside the text/message.

Tibus et al. (2016) stated that academic progress depends on understanding, analyzing, and applying the information gathered through reading. The lack of strong reading comprehension skills affects a students' success in school. The best way to develop the comprehension ability is to expose children to reading in terms of both time and reading materials. The mind needs exercises in the process of digesting ideas and digging deeper into the meaning of things that it gets from reading. Constant reading sessions in school will increase the reading comprehension skills of the pupils. Moreover, reading to them at an early age and asking thought-provoking questions after every reading session would very much likely increase their comprehension ability.

Problem Number 3: Significant difference between the oral and silent reading ability of Grade 7 students

Table 3 shows the result of the test of significant difference between the oral and silent reading ability of Grade 7 students. Table 3 shows the difference between the oral and silent reading ability of Grade 7 students. The probability values are both .000 which is less than the level of significance at .05 . Thus, it can be concluded that there is a significant difference between the oral and silent reading ability of Grade 7 students in fluency and comprehension.

It implies that the oral and silent reading ability of grade 7 students are not the same in fluency and comprehension. In oral fluency, they were able to read the passage but there were some terminologies in the passage which they were not familiar with since the passage dealt with a science concept. There were times that they had to stop reading out of confusion on how to read the words correctly. This was the reason their reading 
Dela Cruz, R. L., \& Recillo, M. L. B.

speed time was extended and which did not comply with the criteria for reading speed set by the Phil-IRI guidelines.

\section{Table 3}

Test of significant difference between the oral and silent reading ability of Grade seven students

\begin{tabular}{cccccccc}
\hline \multirow{2}{*}{ Worksheets } & \multirow{2}{*}{ Test } & \multicolumn{4}{c}{ Paired Differences } & \multirow{2}{*}{ Remarks } & Decision \\
\cline { 3 - 6 } & & Mean & SD & T & $p$ & Reject Ho \\
\hline Fluency & Oral \& Silent & .23333 & .51052 & 5.598 & .000 & Significant & Reject \\
Comprehension & Oral \& Silent & -.21333 & .63019 & -4.146 & .000 & Significant & Reject Ho \\
\hline
\end{tabular}

In terms of word recognition, a great number of participants were categorized to be under the independent level. It shows on the overall results that participants were able to comprehend the passage even if they did not meet the reading speed criteria. The participants' silent reading fluency proved to be faster compared to their oral reading fluency but they comprehended poorly. This only implies that the readers less understood the passage when they did not sound out the words. It supports the observation that decoding skills are the building blocks of successful reading. It is where the reading accuracy and speed come into play. A child with good decoding skills is able to read with speed and accuracy, although not necessarily with good comprehension. However, if the learners have difficulty in decoding, speed is affected, thus, it also follows that comprehension is hampered.

Foorman et al. (2016) quipped that the most commonly used strategy to improve reading fluency is the reading and rereading of familiar texts. Opportunities to read aloud, with guidance from teachers, peers or parents, are also associated with the development of fluent reading. Amendum et al. (2017) reported a similar pattern in which variation in text complexity affects students' rate more than comprehension. Reading ability and text complexity are complementary in that it is the difference between them that affects reading performance, another manifestation of the same phenomenon is that students who read with comprehension will read more slowly when texts are more complex.

Grant (2019) said that there may be a reader who can decode but cannot comprehend or understand what he/she is reading. It is also possible to have a reader who can comprehend and decode but whose oral reading is poor. According to Denton et al. (2011 as cited by Nasibog et al., 2016), learners can comprehend well the information they have read if they read it orally as compared to silent reading. It was expounded by other researcher that when learners read orally, the process of their reading will allow to bound the understanding or comprehending of what they have read because they might focus on how the pronunciation, intonation, and how they are going to read the words correctly.

Problem Number 4: Proposed Enhancement program to improve the reading ability of grade seven students

The enhancement program aims to enhance the reading performance of all the learners who are struggling in their oral and silent reading fluency and comprehension and to improve the frustration and instructional reading level of the learners to independent level. The proposed enhancement program is shown in the succeeding table.

Table 4

Proposed enhancement program in oral and silent reading for Grade 7 students

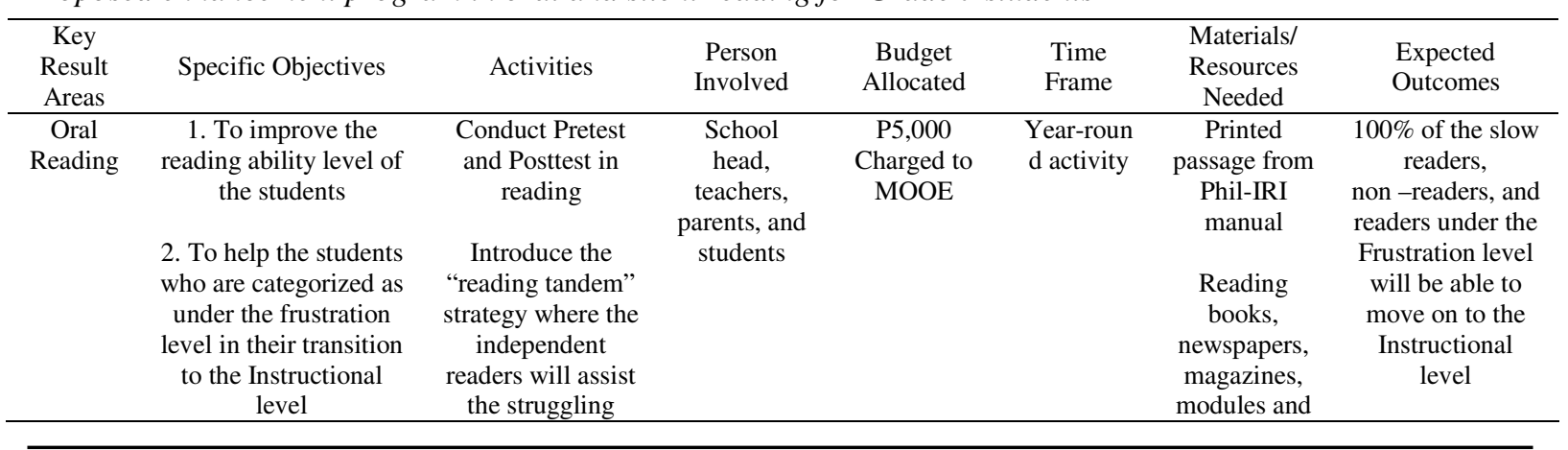

54 Consortia Academia Publishing (A partner of Network of Professional Researchers and Educators) 
The oral and silent reading ability of grade seven students of Calamba Bayside Integrated School

\begin{tabular}{|c|c|c|c|c|}
\hline & $\begin{array}{l}\text { 3. To enhance the } \\
\text { students' oral fluency } \\
\text { and word recognition } \\
\text { 4. To improve the } \\
\text { pronunciation and } \\
\text { enunciation of words } \\
\text { including the } \\
\text { comprehension of the } \\
\text { lines being read }\end{array}$ & $\begin{array}{l}\text { readers. } \\
\text { All subject } \\
\text { teachers have an } \\
\text { everyday spelling } \\
\text { activity of at least } \\
5 \text { words and let } \\
\text { the students } \\
\text { pronounce the } \\
\text { words aloud } \\
\text { before discussing } \\
\text { their lesson. } \\
\text { Conduct every } \\
\text { day the "Pop } \\
\text { Reading" } \\
\text { activities wherein } \\
\text { the students } \\
\text { engage with the } \\
\text { text. Each student } \\
\text { will be asked to } \\
\text { read a part of the } \\
\text { selection }\end{array}$ & $\begin{array}{c}\text { journals } \\
\text { Spelling } \\
\text { notebook } \\
\text { Reading } \\
\text { Power } \\
\text { books, } \\
\text { different } \\
\text { reading } \\
\text { passages } \\
\text { from Phil- } \\
\text { IRI manual }\end{array}$ & $\begin{array}{l}85 \% \text { of the slow } \\
\text { readers, } \\
\text { non -readers, and } \\
\text { readers under the } \\
\text { instructional } \\
\text { level will move } \\
\text { on to the } \\
\text { Independent } \\
\text { level } \\
85 \% \text { of the } \\
\text { learners will } \\
\text { have improved } \\
\text { their spelling } \\
\text { skills. }\end{array}$ \\
\hline $\begin{array}{c}\text { Silent } \\
\text { Reading }\end{array}$ & $\begin{array}{l}\text { 1. To enhance the } \\
\text { reading fluency of the } \\
\text { students in silent } \\
\text { reading } \\
\text { 2. To increase the } \\
\text { reading proficiency of } \\
\text { the students } \\
\text { 3. To enrich the } \\
\text { students' vocabulary } \\
\text { 4. To enhance the } \\
\text { reading } \\
\text { comprehension of the } \\
\text { learners who were } \\
\text { categorized as under } \\
\text { the frustration and } \\
\text { instructional levels } \\
\text { 5.To develop } \\
\text { appropriate learning } \\
\text { experiences } \\
\text { 6. To address learners' } \\
\text { needs, interest, and } \\
\text { experiences in reading. }\end{array}$ & 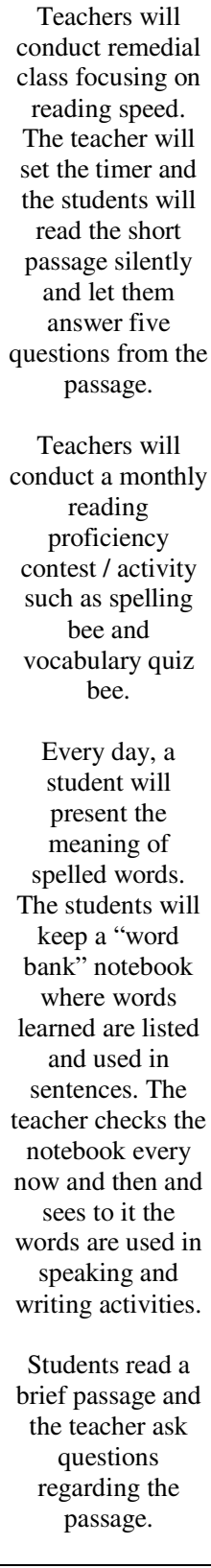 & $\begin{array}{l}\text { White board, } \\
\text { white board } \\
\text { marker, } \\
\text { eraser, pentel } \\
\text { pen, list of } \\
\text { words } \\
\text { according to } \\
\text { range of } \\
\text { difficulty per } \\
\text { level. } \\
\text { Pocket } \\
\text { dictionary } \\
\text { and word } \\
\text { bank } \\
\text { notebook } \\
\text { Different } \\
\text { reading } \\
\text { passages } \\
\text { from Phil - } \\
\text { IRI manual } \\
\text { and books } \\
\text { Book } \\
\text { shelves, set } \\
\text { of mini table } \\
\text { and chairs, } \\
\text { and various } \\
\text { printed } \\
\text { materials }\end{array}$ & 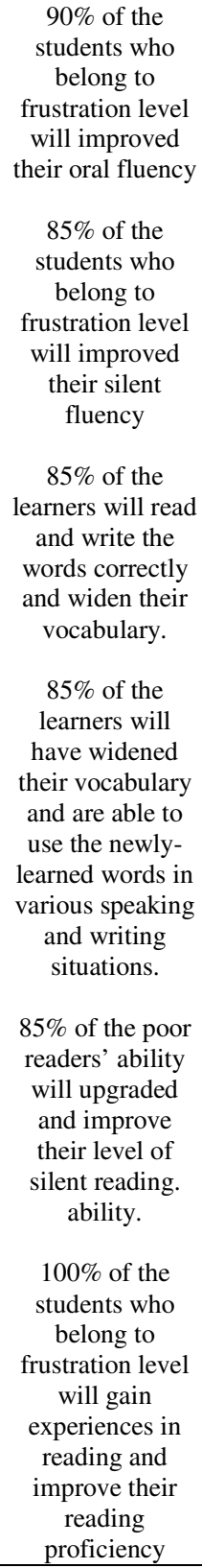 \\
\hline
\end{tabular}




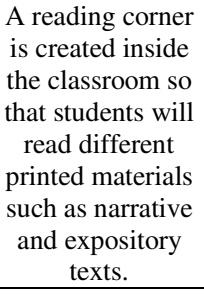

\section{Conclusions}

Based on the findings of the study, the following conclusions were derived:

$>$ That in terms of oral reading speed/fluency, majority of the students read laboriously at a slow pace and with frequent pauses, repetitions of sounds or syllables, or hesitations which all mean that the student were concentrating hard to tap their phonics knowledge to make sense of the text; and since they struggled in reading the material, they received extensive support and instruction from the teacher and were able to understand the materials, meaning they had difficulty in reading (dyslexia) but not in understanding (comprehension - the process was challenging for them, but they managed.

$>$ That in terms of silent reading speed/fluency, a great number of the respondents were slow in speed and so they struggled with the material and took a longer time for them to finish it; while in terms of comprehension, they could not understand some of the words of the material since they did not have adequate background level of the topic and re-read the material, thereby reducing their ability to recall what they read; thus, they required extensive assistance from their teacher.

$>$ That as far as the difference in their oral and silent reading ability was concerned, in terms of fluency, there was no difference for they were all classified under the frustration level in both oral and silent reading; but there was a significant difference in terms of comprehension for they read better aloud (instructional level - since they were helped by their teacher while reading) than quietly (frustration level - when they were on their own).

\subsection{Recommendations}

The researcher offers the following recommendations based on the conclusions derived from the results of analysis of the data gathered.

1. Oral reading involves pronunciation, enunciation, articulation, and pacing and considering that the language used by the students is foreign and difficult to read, those students may have difficulty with decoding skills or they may just need more practice with speed and smoothness in reading.

$\diamond \quad$ For fluency, teachers have to assist the slow students to perform at their current level rather than at their grade level and with the provision of appropriate texts; the goal then is to help them transition from being struggling readers to being good readers. Activities may consist of the following to emphasize word recognition accuracy (decoding written words into oral), automaticity (rate of reading), and prosody (reading with expressions): modeling, imitating, repeating or re-reading, choral reading, guided oral reading, immediate correcting, intensive training on word recognition, decoding with vocabulary, and using technology-aided authentic listening materials coupled with appropriate speed, phrasing, correct expression and intonation, chunking of words in thought units, and using punctuation-influenced intonation in reading texts: all to facilitate fluency development.

$\diamond$ For comprehension, readers but may have difficulties with many comprehension-related standards, and although they can decode grade-appropriate texts, they may need considerable teacher scaffolding in order to comprehend them; thus, they need interventions focused on the specific comprehension areas in which they are weak The following activities may help: teaching decoding with vocabulary, 
The oral and silent reading ability of grade seven students of Calamba Bayside Integrated School

obtaining word knowledge and making words part of students' everyday language, using oral language in a listening comprehension exercise, identifying key points in texts, constructing a summary, using graphic organizers teach text structure.

2. The Silent reading fluency and comprehension of the student-respondents were both assessed as in the frustration level; so the results somehow suggest that fluent reading of text affects word decoding and expectedly, reading comprehension. In this case, the researcher recommends a blended intervention for fluency and comprehension difficulties of students in silent reading and involving all major stakeholders (adapted from Reading Rockets, 2020):

$\diamond \quad$ Students. Track the words with their finger as a parent or teacher reads a passage aloud; then they read it. Have a parent or teacher read aloud to them; then, match their voice to that of the source. Read favorite books and poems repeatedly; practice getting smoother and reading with expression.

$\diamond \quad$ Parents. Support and encourage their children; realize that they are likely frustrated by reading. Check with their children's teachers to find out their assessment of their children's word decoding skills. If their children can decode words well, help them build speed and accuracy by reading aloud and having them match their voice to that of the parents; having the children practice reading the same list of words, phrase, or short passages several times; reminding their children to pause between sentences and phrases; read aloud to their child to provide an example of how fluent reading sounds; give their children books with predictable vocabulary and clear rhythmic patterns so they can "hear" the sound of fluent reading as they read the book aloud; and use books on tapes and have the children follow along in the print copy.

$\diamond \quad$ Teachers. Assess the students to make sure that word decoding or word recognition is not the source of the difficulty (if decoding is the source of the problem, decoding will need to be addressed in addition to reading speed and phrasing). Give the students independent level texts that they can practice again and again. Time the students and calculate words-correct-per-minute regularly. The students can chart their own improvement. Ask the students to match their voice to that of the teacher's when reading aloud or to a tape-recorded reading. Read a short passage and then have the students immediately read it back to the teacher. Have the students practice reading a passage with a certain emotion, such as sadness or excitement, to emphasize expression and intonation. Incorporate timed repeated readings into the instructional repertoire. Plan lessons that explicitly teach students how to pay attention to clues in the text (for example, punctuation marks) that provide information about how that text should be read.

3. The results in the silent reading assessment should concern not only the researcher and other English teachers but the entire educational system as they have a far-reaching effect in the reading assessments done globally. The DepEd (or any concerned government agency) or the schools should also institute a program or any action that will complement the effort of creating PHL-IRI that was used in this study that informally measured the strengths and weaknesses of the students' reading ability; this time it should be an assessment that determine the type of oral and silent reading difficulties that the students have. This will hopefully minimize or eliminate the difficulties since the complementary effort will address the specific difficulty that each learner faces.

$\diamond \quad$ The Department of Education should provide more reading materials to cater the students who are in the frustration level. Further, it should also consider assigning reading experts in every school.

$\diamond \quad$ In addition, the enhancement program developed by the researcher should be tried as an instrument to improve the oral and silent reading ability level of the students in terms of fluency and comprehension.

$\diamond \quad$ Future researchers may focus on the determination of the types of reading difficulties students have 
after the assessment instruments for such have been crafted by the education officials in the country.

\section{References}

Alokan, F. B., Osakinle, E. O., \& Onijingin, E. O. (2013). The influence of parents' educational background and study facilities on academic performance among secondary school students. Retrieved from https://ozelacademy.com/ojss.v6.i2-1.pdf

Alphonse, J. R., \& Leblan, R. (2014). Integrating vocabulary instruction with reading comprehension strategies. Toronto, USA.

Amendum, S. J., Conradi, K., \& Hiebert, E. (2017). Does text complexity matter in the elementary grades? A research synthesis of text difficulty and elementary students' reading fluency and comprehension. Educational Psychology Review, 1-31. https://doi.org/10.1007/s10648-017-9398-2

Ankrum, J. W., Genest, M. T., \& Belcastro, E. G. (2014). The power of verbal scaffolding: "Showing” beginning readers how to use reading strategies. Early Childhood Education Journal, 42(1), 39-47. https://doi.org/10.1007/s10643-013-0586-5

Bernardo, A. S. (2013). Developmental reading. Rex Bookstore Inc.

Bernardo, A. S. (2015). Developmental reading 2 ( $1^{\text {st }}$ ed.). Rex Bookstore Inc.

Betty, E. A. (2009). Reading strategy instruction: Its effects on comprehension and word inferences ability. Online ERIC ED506765. Journal of Education and Practice, 6(27).

Cabardo, J. O. (2014). Reading proficiency level of students: Basis for reading intervention program. https://doi.org/10.2139/ssrn.2712237

Cerado, M. N., Latigo, L. T., \& Pagdato Jr., D. A. (2018). Factors affecting the reading ability of grade 7 students: Basis for reading enhancement program of the school.

Chen, H -Y. (2009). Strategies and special education elementary and middle school students [PhD Dissertation], Michigan State University.

Daniel, M. H. (2014). A new measure of silent reading fluency with comprehension. Paper presented at the annual meeting of the National Association of School Psychologists, Washington, DC.

Davis, Y. T., Datulayta, F. M. C., Dacalos, J. S., Cordova, B. B., Clerigo, K. A., Canoy, N. E., \& Inocian, R. B. (2016). Effective teaching practices in handling nonreaders. Asia Pacific Journal of Multidisciplinary Research, 4(3).

Denton, C. A., Barth, A. E., Fletcher, J. M., Wexler, J., Vaughn, S., Cirino, P. T., \& Francis, D. J. (2011). The relations among oral and silent reading fluency and comprehension in middle school: Implication for identification and instruction of students with reading difficulties. Scientific Studies of Reading, 15(2), 109-135. https://doi.org/10.1080/10888431003623546

Education Endowment Foundation (2017). EEF Projects. London: Education Endowment Foundation.

Espejo, C. T., Macahilig H. B., \& Gutierrez M. M. (2016). The comprehension level of selected grade four pupils vis-à-vis text and test types in Filipino. The Normal Lights, 10(1).

Estrada J. A. (2016). The level of English oral reading fluency among Abot - Alam secondary learners. World Journal of English Language, 6(3). https://doi.org/10.5430/wjel.v6n3p9

Fitzer, K., \& Hale, J. (2015). Reading and the brain: Strategies for decoding, fluency and comprehension. Toronto, USA. Retrieved from https://www.ldatschool.ca/teaching-the-brain-to-read-strategies-for-enhancingreading-decoding-fluency-and -comprehension/

Foorman, B., Beyler, N., Borradaile, K., Coyne, M., Denton, C. A., Dimino, J., Furgeson, J., Hayes, L., Henke, J., Justice, L., Keating, B., Lewis, W., Sattar, S., Steke, A., Wagner, R., \& Wissel, S. (2016). Foundational skills to support reading for understanding in kindergarten through 3rd grade. (NCEE 2016 4008). Washington, DC: National Centre for Education Evaluation and Regional Assistance, Institute of Education Sciences, US Department of Education.

Georgiou, G. K., \& Das, J. P. (2012). Reading comprehension in university students: Relevance of PASS theory of intelligence. Journal of Research in Reading. https://doi.org/10.1111/j.1467-9817.2012.01542.x 
The oral and silent reading ability of grade seven students of Calamba Bayside Integrated School

Gilakjani, A. P., \& Sabouri, N. B. (2016). A study of factors affecting EFL learners' reading comprehension skill and the strategies for improvement. International Journal of English Linguistics, 6(5), 180. https://doi.org/10.5539/ijel.v6n5p180

Gillaco M. M. (2014). Level of word recognition and reading comprehension: A basis for a reading program. Asia Pacific Journal of Education, Arts and Sciences, 1(5).

Graham, K. (2015). An investigation of the cover, copy, compare method for EFL student. Language Education in Asia, 6(1). https://doi.org/10.5746/LEiA/15/V6/I1/A7/Graham

Grant M. (2019). Reading intervention: Programs, strategies and activities. Retrieved from https://study.com/academy/lesson/reading-intervention-programs-strategies-and activities.html

Habibian, M., \& Roslan, S. (2014). The relationship between self-efficacy in reading with language proficiency and reading comprehension among ESL learners. Journal of Education and Science, 5(4), 119-126.

Head, R., \& Leblanc, R. (2014). Effective vocabulary strategies for students with learning disabilities. Toronto, USA.

Hingpit, R (2014). Module 2: Theories of reading instruction. Retrieved from https://erwincoquilla.wordpress.com/2014/11/14/module-2theories-of-reading-instruction

Homer, B. D., Kinzer, C. K., Plass, J. L., Letourneau, S. M., Hoffman, D., Bromley, M., \& Kornak, Y. (2014). Moved to learn: The effects of interactivity in a Kinect based literacy game for beginning readers. Computers \& Education, 74, 37-49. https://doi.org/10.1016/j.compedu.2014.01.007

LaBerge, D., \& Samuels, S. A. (1974). Toward a theory of automatic information processing in reading. Cognitive Psychology, 6, 293-323. https://doi.org/10.1016/0010-0285(74)90015-2

Lysenko, M., \& Abrami, J. (2014). An analysis of ESL, children's verbal interaction during computer book reading. Computers in the Schools, 13(3/4), 55-73. https://doi.org/10.1300/J025v13n03_06

Miñoza M. V., \& Montero, M. A. (2019). Reading comprehension level among intermediate learners. Science International (Lahore), 31(3), 561-568.

Naglieri, \& Reardon. (1993). Traditional IQ is irrelevant to learning disabilities - intelligence is not. American Psychological Association. https://doi.org/10.1177/002221949302600205

Nasibog E. C., \& Telan, R. A. (2016). Reading rate and reading comprehension among grade three students. The University of Mindanao, Davao City.

National Reading Panel. (2000). Teaching children to read: An evidence-based assessment of the scientific research on reading and its implications for reading instruction. Washington, DC: National Institute of Child Health and Human Development 3-5.

Neff, N., S., \& Vaughan, C. (1999). Improving reading comprehension at the first grade level. Master of Arts in Teaching and leadership.

Panayiota, K., Papadopoulos, T. C., \& Spanoudis, G. (2016). Reading comprehension and PASS theory. Department of Educational Psychology, University of Minnesota, Minneapolis.

Pardo. (2014). Supplemental reading instruction for students at risk for reading disabilities: Improve reading 30 minutes at a time. Learning Disabilities, South Dakota.

Paz, P. A. (2018). Reading comprehension levels in English among grade 7 students in Caraga State University, Butuan City, Philippines. Phil-IRI Manual of Administration.

Punsalan, M. W. (2006). Fluency in the high school classroom: One teacher's method. Adolescent Literacy in Perspective, 5-7.

Rasinski, T. (2010). Reading fluency for adolescents: Should we care? Adolescent Literacy in Perspective, 3-5. Retrieved from https://wjel.sciedupress.com

Rasinski, T., Paige, D., Rains, C., Stewart, F., Julovich, B., Prenkert, D., \& Nichols, W. D. (2017). Effects of intensive fluency instruction on the reading proficiency of third-grade struggling readers. Reading \& Writing Quarterly, 1-14. https://doi.org/10.1080/10573569.2016.1250144

Robinson, D., \& Randall L. (2016). Social justice in physical education: Critical reflections and pedagogies for change. Canadian Scholars' Press Toronto.

Rocero, A. R., \& Macha, J. L (2014). Reading comprehension intervention program of University of Perpetual Help System Laguna. 
Dela Cruz, R. L., \& Recillo, M. L. B.

San Juan, R. (3 December 2019).

https://wwwphilstar.com/headlines/2019/12/03/1974002/philippines-lowest-reading-comprehensionamo ng79countries\#wB860qbOltKqrv

Schnoll, R. (2012). Chocolate: Food for the Gods. Retrieved from

http://academic.brooklyn.cuny.edu/health/rschnoll/contact/documents/chocolatefacultycircle

Snowling, M. J., (2014). Dyslexia: A language learning impairment. University of Oxford. https://doi.org/10.5871/jba/002.043

Tibus, E. D., \& Pobadora, R. L. (2016). Reading comprehension ability vis-a-vis demographics. Reading Materials, and Time Spent in Reading, 5(9), 66-74. https://doi.org/10.18533/journal.v5i9.1002

Trainin, G., Hiebert E. H., \& Wilson K. M. (2015). A comparison of reading rates, comprehension, and stamina in oral and silent reading of fourth-grade students. https://doi.org/10.1080/02702711.2014.966183

University of Utah Reading Clinic. (2015). Reading levels. Retrieved on from http://www.uurc.utah.edu/General/ReadLevels.php

Vorstius, C., Radach, R., \& Lonigan, C. J. (2014). Eye movements in developing readers: A comparison of silent and oral sentence reading. Visual Cognition, 22(3), 458-485.

https://doi.org/10.1080/13506285.2014.881445

Westby. (2012). Using higher order questioning to accelerate students' growth in reading. The Reading Teacher, 65(5), 30. https://doi.org/10.1002/TRTR.01045 